\title{
A CONSTRUÇÃO DO PROJETO DE VIDA DO ALUNO DA REDE PÚBLICA DE EDUCAÇÃO
}

\section{Construction of Life Projects Among Students of the Public System of Education}

Graziele Aline Zonta ${ }^{1}$

\section{Resumo}

Este trabalho teve por objetivo verificar o modo como os alunos de ensino médio da rede pública de educação têm construído os seus projetos de vida. Os dados foram coletados em dois momentos: por meio de entrevistas com alunos de $3^{\circ}$ ano do ensino médio e por depoimentos de alunos de $2^{\circ}$ ano que, na ocasião, participavam de grupos de orientação profissional em uma escola da cidade de Curitiba, PR. Os dados coletados com as entrevistas foram submetidos a uma análise do conteúdo do discurso dos sujeitos que teve por finalidade compreender os sentidos que norteiam a definição dos objetivos de vida destes jovens. Como resultado, verificou-se que possuir uma profissão é o principal objetivo estabelecido, o que, segundo os estudantes, será alcançado unicamente através do esforço individual. De acordo com a percepção dos alunos, a escola pública não tem se constituído como espaço para reflexão e discussão acerca de si mesmos e sua relação com o mundo, nem para certificá-los ou instrumentalizá-los para o mundo do trabalho ou para a Universidade. Os resultados também evidenciaram que os projetos de vida apresentados não os constituem enquanto sujeitos para si, mas para a reprodução do modelo de sociedade estabelecido. Palavras-chave: Projeto de vida; Ensino médio; Trabalho; Educação.

\section{Abstract}

This study aimed to verify how the high school students of the public system of education have been building their life projects. The data was collected in two moments: interviews with students of the $3^{\text {rd }}$ year of high school and testimonies of students of the $2^{\text {nd }}$ year of high school who were participating in groups of career guidance that occurred at a school in the city of Curitiba, PR. The content collected through the interviews was analysed with the intention of understanding the meanings that guide the establishment of goals by these students. As a result, it was verified that the main goal set is the professional definition, which would be accomplished through individual effort. The public school has not been serving as a place for reflection and discussion for these students, neither to prepare them for labor or the University. It was also verified that the students do not present themselves as subjects of their life projects, but reproducing the established model of society.

Keywords: Life projects; High school; Labor; Education.

Especialista em Psicodrama Terapêutico da Universidade Federal de Santa Catarina. Florianópolis, SC. e-mail: gzonta@hotmail.com 


\section{Introdução}

A escolha profissional é um tema freqüente entre os alunos que ingressam no Ensino Médio. Nesse momento, o serviço de Orientação Profissional realizado por profissionais da área de psicologia costuma ser ofertado na tentativa de auxiliar o jovem na escolha de um caminho a seguir. Entretanto, discute-se atualmente, que mais importante do que ajudar o estudante a somente escolher uma profissão, a psicologia deve auxiliá-lo na reflexão sobre as suas relações com o mundo, abrindo caminhos para a definição de objetivos nos seus diferentes papéis sociais, além do papel profissional, e construindo assim um projeto de vida calcado na realidade.

\section{A construção do projeto de vida}

Autores como Liebesny e Ozella (2002) consideram que o jovem constrói suas formas de perceber o mundo por meio da interiorização dos valores que constituem suas diferentes formas de relação com os outros. Assim, ele constitui um sentido para a sua realidade vivida, para a sua atividade e irá diferenciar seu modo de ser agente nas relações, construindo, dessa forma, o seu processo de individuação. E será a consciência a responsável pela mediação entre as realidades objetiva e subjetiva do sujeito.

Ao considerar que as construções internas, subjetivas se dão a partir da atividade externa nas relações sociais, questiona-se: Que condições estão sendo dadas para que o jovem se torne sujeito do seu próprio projeto, ou seja, construa um projeto elaborado por ele, de forma consciente? Atualmente, os valores sociais, cujos significados são subjetivados na constituição de sentidos para o sujeito, têm se traduzido em competitividade, reconhecimento pelo que se possui em detrimento do que se é, responsabilidade unicamente individual pelo alcance de sucesso em detrimento da discussão das determinações sociais, desresponsabilização de cada um pelo conjunto social, destituição do outro como sujeito de respeito, não reconhecimento da alteridade que nos constitui. Tais valores individualistas fazem com que o jovem se veja responsável somente por si mesmo e não pelas conseqüências sociais de sua atividade. Deste modo, o jovem não se vê como sujeito da própria ação, não questiona ou vê a possibilidade de transformar a realidade do mundo atual, tornando-se objeto das suas relações. (Liebesny e Ozella, 2002).

Contini (2001) também atribui um importante papel à consciência no que se refere à construção de um projeto de vida. Para esta autora, a construção de um projeto se realiza a partir da tomada de consciência do sujeito de que ele faz parte de um todo social. E acrescenta que, sendo a instituição de ensino parte e reflexo do contexto social, a tomada de consciência pode ser incentivada por meio de um processo educacional que permita a reflexão sobre as determinações afetivas, sociais, econômicas, da sua existência. Assim, a reflexão que leva à construção de um projeto de vida se dará diferentemente para o jovem da escola pública e para o da particular, visto que as condições sociais e a relação destes jovens com o trabalho são diferentes.

Diante deste quadro, este estudo se propôs a verificar quais objetivos os alunos do Ensino Médio da rede pública de ensino incluem em seus projetos de vida e de que modo tais objetivos são definidos. Para tanto, buscou-se compreender os valores sociais que são subjetivados pelo jovem e de que modo a escola pública tem se constituído como instrumento para realização destes projetos.

\section{A bistória da educação brasileira e o princípio liberal de educação}

Aceitando-se que a escola reflete a realidade social em que o jovem está inserido além de desempenhar um importante papel na constituição da sua subjetividade, torna-se essencial a compreensão do desenvolvimento histórico e da situação atual do ensino público no Brasil, em particular do Ensino Médio. Atualmente, o ensino público é alvo de um olhar negativo, construído ao longo de várias décadas de ações políticas, em que prevaleceu a falta de investimento na educação pública, que por sua vez deram origem ao sucateamento e a uma conseqüente desvalorização da escola pública.

Em seu estudo sobre a história da educação no país, Ghiraldelli Jr. (2001) nos mostra que, já nas primeiras repúblicas, a defesa pelo investimento nas escolas secundárias, em detrimento das escolas primárias, atendia às necessidades dos filhos das classes altas que já haviam cursado uma escola primária particular. 
Também a defesa da profissionalização da escola pública iniciada na década de 30 , reafirmada na década de 50 e ampliada durante a ditadura permitiu representar a divisão de classes da sociedade capitalista, mantendo o filho do trabalhador no seu lugar de trabalhador. Isso, aliado às políticas de educação popular que se resumiram, ao longo da história, à eliminação do analfabetismo das massas para fins eleitorais, já delineava o destino da escola pública primária de ter como clientela as classes economicamente baixas.

A baixa qualidade do ensino público se deve também ao desencargo dos poderes públicos de manter e expandir o ensino a toda a população. A Carta Magna de 1937 se encarregou de retirar tal obrigação, que havia sido instituída pela Carta de 1934. Da mesma maneira, o Plano Nacional da Educação, que também responsabilizava o governo pela aplicação de recursos na educação, foi derrubado pelo golpe de 64. (Ghiraldelli Jr., 2001)

A ditadura de 64 foi, portanto, a oficialização de uma tendência construída ao longo da história da educação no Brasil: uma escola pública destinada a fornecer uma profissão à classe trabalhadora e um ensino superior destinado aos filhos das classes altas. Encarregou-se também de dar uma contribuição ainda maior para o já desigual sistema de ensino brasileiro, levando o ensino público ao nível do impraticável pela total falta de estrutura para implantação de tal sistema.

A desvalorização resultante do processo histórico de sucateamento da instituição não é o único desafio que a educação pública tem que enfrentar atualmente. O discurso da ideologia liberal se apresenta como um forte aliado para impedir a transformação da realidade educacional se encarregando de dissimular a discriminação de classes.

O princípio ideal liberal de educação assume que a escola não deve privilegiar a nenhuma classe, nem ser um instrumento aristocrático para servir a quem possui tempo e dinheiro. A escola, independentemente da família, classe ou religião a que pertença, deve desenvolver os dotes, valores intrínsecos, aptidões e vocações de cada indivíduo. Será a partir do desenvolvimento destas aptidões, valores, etc. que cada um encontrará o seu lugar na estrutura ocupacional existente e, portanto, sua posição na sociedade. Porém, sabe-se que o sistema capitalista não dá as mesmas oportunidades a cada indivíduo de desenvolver as suas capacidades. Dessa forma, um sistema de discriminação se esconde por trás da ideologia liberal que, por sua vez, tem sido reproduzida pela escola. (Cunha, 1985).

Kuenzer (2000) acrescenta que a crença nas "diferentes competências" que exigem diferentes modalidades e níveis de educação é utilizada como meio de justificativa para a redução da presença do Estado no seu financiamento. Assim, a concepção de universalidade do direito de acesso e permanência a todos os níveis e modalidades de educação é substituída pela concepção de eqüidade, em que cada um deve receber o papel que irá desempenhar na sociedade de acordo com a sua competência.

Também cabe aqui ressaltar as particularidades do ensino médio na escola pública. O ensino médio é um nível de ensino historicamente marcado pelo enfrentamento de diversos desafios. Kuenzer (2001) ressalta o talvez maior deles: a ambigüidade contida na função do ensino médio, que deve preparar para o mundo do trabalho, ao mesmo tempo em que prepara para a continuidade dos estudos. A autora ressalta que tal dualidade não pode ser resolvida somente no âmbito filosófico e metodológico, visto que se trata de um problema político resultante das relações de poder típicas de uma sociedade de classes, às quais se atribui o desempenho das funções intelectuais e dirigentes, ou o exercício das funções instrumentais.

Foi assim que a Lei de Diretrizes e Bases da Educação Nacional (LDB) de 1996 concretizouse como o resultado de anos de produção científica na área pedagógica. Construída de maneira ampla e democrática, apresenta a característica de tratar o Sistema Educacional em sua dimensão de totalidade, propondo uma educação básica comum para todos os cidadãos. A nova lei aceita a dimensão pedagógica do trabalho, a necessidade de articulação entre educação escolar, o mundo do trabalho e prática social. Tem como pressuposto o fato de que a educação profissional só é possível por meio de uma base sólida de educação geral, "uma vez que o fim da educação é preparar o cidadão para se constituir como humanidade participando da vida política e produtiva." (Kuenzer, 2000, p. 30).

Entretanto, a aparente superação da dualidade educacional contida neste discurso da nova LDB passa a ser questionada a partir do momento em que ela admite a criação de um sistema de educação profissional de nível técnico paralelo ao ensino médio. Criado pela SEMTEC, este ensino é oferecido concomitantemente ou seqüencialmente ao ensino médio, por instituições públicas federais, 
estaduais, municipais ou privadas. $\mathrm{O}$ aluno que deseja cursar o ensino técnico deve agora concluir também o ensino médio na escola "normal".

Ao criar estas duas redes de educação, retomam-se as antigas questões por tanto tempo alvo de discussão. Volta-se a aceitar que nem todos possuem competência acadêmica, necessitando de uma educação complementar para se tornar produtivo. Finalmente, considera-se novamente a dualidade estrutural já discutida: a de que existe um tipo de conhecimento acadêmico voltado para o aprendizado da teoria e o conhecimento tecnológico avançado que, desvinculado dos conhecimentos acadêmicos, encontra-se diretamente relacionado ao trabalho.

\section{A construção do autoconceito}

Diante deste quadro, é possível considerar que as metas estabelecidas no projeto de vida de um aluno de escola pública sofram a influência da consciência deste aluno das condições limitadas desta instituição e dos significados a ela atribuídos, já que dela ele faz parte. Assim, é importante discutir a influência do autoconceito do jovem na formação do seu projeto de vida, visto que o autoconceito ajuda a definir até onde o indivíduo acredita que pode chegar.

A compreensão da formação do autoconceito se inicia a partir do estudo da construção de significados, pois é a partir da construção de significados que o ser humano reflete a sua realidade e faz suas escolhas. O significado é um fenômeno da união entre palavra e pensamento, que se materializa por meio da fala que, por sua vez, expressa nosso pensamento, que carrega nossos desejos, necessidades, interesses e emoções. (Vygotsky, 1992).

Se a motivação constrói o pensamento e este expressa os significados, então o autoconceito seria constituído dos significados que o indivíduo possui de si mesmo. Esses significados podem receber uma valoração adequada, subvalorizada ou supervalorizada, por meio de um processo que se inicia desde a infância. Rey (1995) aponta que um autoconceito subvalorizado gera o sentimento de insegurança e pode resultar dos constantes fracassos escolares, do julgamento dos pais e professores e da autodesvalorização das próprias capacidades. A expectativa de fracasso, que possuem conscientemente os jovens de autoconceito subvalorizado, afeta não somente os resultados de suas atividades como também a sua preparação para elas, pois estes se mostram com freqüência descrentes de obter bons resultados. É comum que estes alunos subvalorizem as tarefas escolares, limitando a formação de interesses escolares e profissionais, assim como de qualidades como a disciplina, o coletivismo e a afabilidade.

De forma semelhante se constrói o autoconceito supervalorizado. Nesse caso, a valorização exagerada é construída na medida em que, desde a infância, o indivíduo recebe uma valorização demasiadamente elevada que ressalta suas capacidades e virtudes sobre os demais colegas, sem conter nenhum tipo de crítica ou análise objetiva das qualidades que conduzem ao êxito. Esse desenvolvimento desmedido da necessidade de autovalorização faz com que o reconhecimento dos outros passe a ocupar o lugar central na motivação do sujeito, de modo que se constrói a necessidade de ocupar uma posição mais destacada do que os demais jovens. O mesmo não ocorre com jovens que possuem êxito escolar, mas cujo autoconceito não se baseia em princípios individualistas. Nestes jovens, o autoconceito é baseado nas suas concepções de mundo e de si mesmos, que determinam uma forte convicção de qual deve ser a sua posição frente ao fracasso. (Rey, 1995).

\section{Método}

Esta pesquisa se constitui de um estudo de caso, no qual foram abordados sujeitos de uma escola pública da cidade de Curitiba no ano de 2004. Os dados foram coletados em dois momentos: 1. Depoimentos de alunos do $2^{\circ}$ ano do Ensino Médio coletados durante as discussões em grupos de Orientação Profissional. Esses grupos funcionaram como grupos focais em que alguns temas, levantados a partir do referencial teórico, foram propostos e discutidos. 2. Entrevistas semiestruturadas com quatro jovens (dois do sexo feminino e dois do sexo masculino) do $3^{\circ}$ ano do Ensino Médio que não participaram dos grupos de orientação profissional. A diferença de gênero foi considerada pela possibilidade de levantar questões de análise neste nível. A realização destas entrevistas se deu pela possibilidade de obter dados diferentes daqueles coletados durante o trabalho de orientação profissional, por meio de uma população que não estava passando pelo processo de reflexão e 
discussão proposto nos grupos. Os dados obtidos com as entrevistas foram submetidos à análise do conteúdo do discurso dos alunos.

\section{Resultados e discussão}

Nesta sessão, os comentários entre aspas representam a fala dos sujeitos participantes.

Objetivos traçados e as dificuldades de se escolher uma profissão.

O principal objetivo apontado pelos jovens, na elaboração do projeto de vida, diz respeito à realização profissional. Nota-se que grande parte dos alunos que procuram espontaneamente pelo serviço de orientação profissional o fazem por estar em dúvida quanto ao curso universitário que desejariam cursar. Tal fato pode refletir a crença de que o serviço de Orientação Profissional se destina à escolha de um curso superior e não à elaboração de projetos de vida, ou à definição de carreiras que não incluam necessariamente a passagem pela Universidade. A independência financeira aparece como segundo objetivo no projeto de vida dos jovens participantes e a constituição de uma família, quando aparece como objetivo, é considerada apenas após a realização profissional.

Quanto aos obstáculos percebidos pelos jovens na escolha de um caminho profissional, os principais foram: o mercado de trabalho competitivo, a falta de conhecimento real sobre as carreiras consideradas e a falta de autoconhecimento. Quanto à concorrência no mercado, aparece fortemente a crença em um mercado selvagem marcado não somente pelo grande número de profissionais em áreas de pouca demanda, mas também pela inveja daqueles que não conseguem alcançar boa posição neste mercado. Para estes alunos, os profissionais que não se dedicam o suficiente para conseguir uma boa colocação no mercado prejudicam os profissionais mais dedicados, a fim de roubar o seu lugar.

A proposta de solução que os alunos apresentaram para a dificuldade da competição profissional é se preparar para ser o melhor competidor e não perder espaço para aqueles que possam tentar assumir o seu lugar. Esse discurso reflete que os jovens possuem consciência da concorrência no mercado de trabalho, mas essa concorrência não está articulada ao contexto social que oferece mais oportunidades a alguns indivíduos, e sim ao esforço pessoal de cada um, deixando transparecer os valores individualistas internalizados.

Fica ainda evidente no discurso destes jovens que a escolha de uma profissão significa a escolha de uma atividade produtiva para si, que garanta o sustento das suas vidas, sendo desconsiderado o compromisso social que envolve a escolha de uma profissão. Esta situação ilustra a dificuldade de localizar o mundo do trabalho dentro do contexto social e de refletir sobre a função social das profissões, o que fica ainda mais claro quando os alunos manifestam a idealização de algumas carreiras profissionais que carregam a crença de oferecer um bom retorno financeiro. Nesse caso, foram citadas principalmente as carreiras de medicina e direito. O médico é definido pelos alunos como o profissional que entende da saúde, o que mais estuda, mais trabalha e tem o melhor salário, sendo desconsiderado o papel social do médico ou a sua situação na atuação em saúde pública, por exemplo. Esses dados mostram que as ideologias das profissões parecem ser mais determinantes na escolha profissional do que os dados de realidade, principalmente devido à falta de conhecimento real das áreas de atuação e das próprias habilidades pessoais que poderiam contribuir ou não para a atuação nas profissões escolhidas.

A exceção é feita aos jovens que por já trabalharem na área escolhida - oferecida pelos cursos técnicos - possuem conhecimento maior das necessidades exigidas pela profissão já definida, bem como do mercado de trabalho. Para esses jovens, a escola não oferece um espaço para discussão acerca do mundo do trabalho, de modo que o jovem parece apenas ter um conhecimento não idealizado das profissões quando já está em contato direto com ela, seja por meio de um emprego ou do curso profissionalizante.

\section{A escola pública enquanto instrumento}

O sentimento de desvantagem com relação ao ensino, quando comparados aos alunos da escola particular, aparece como principal obstáculo para aqueles que vêem na Universidade um caminho para o sucesso profissional. Isso é observado na crença manifestada de que o aluno da escola particular "aprende mais rápido". Os jovens justificam tal 
afirmação expressando que os professores da escola pública não dão aulas tão bem quanto os da particular e o conteúdo visto na escola pública não acompanha o conteúdo daquela, que é mais adiantado.

Para os alunos que desejam fazer faculdade e que possuem condições financeiras, a solução encontrada é o cursinho pré-vestibular, que é cursado paralelamente ao terceiro ano do ensino médio. Alunos que já freqüentaram a escola particular ou o cursinho pré-vestibular afirmam que na particular o conteúdo do vestibular é oferecido "todo mastigado", enquanto que na escola pública, o aluno recebe somente o conteúdo do terceiro ano, "e olhe lá". Esta desvantagem reflete significativamente na escolha da universidade que estes alunos decidem cursar. Até mesmo para os alunos de boas condições financeiras e autoconceito elevado, ou seja, que acreditam na possibilidade de fazer a formação universitária, a possibilidade de cursar uma Universidade Federal parece improvável, pois os alunos da escola pública acreditam que não teriam condições de passar no concorrido vestibular. A Universidade gratuita parece ser deixada, portanto, para os alunos de escolas particulares que possuem melhores condições de competição no processo seletivo.

Já para aqueles que dirigem a profissionalização para outro caminho que não a Universidade, acrescentam-se os obstáculos frente à obtenção de estudo superior, a necessidade de trabalhar, já iniciada durante a adolescência, e a falta de recursos financeiros. Para esses alunos, o caminho escolhido é um curso técnico-profissionalizante cursado paralelamente ao ensino médio. Como para ter o diploma do curso técnico reconhecido é requisitada a conclusão do ensino médio, estes alunos vêem na escola pública um instrumento para obter o título da escola profissionalizante, mas não a vêem como fornecedora do embasamento para a formação profissional.

Ressalta-se no discurso destes estudantes a confiança que todos depositam no esforço individual como caminho para o sucesso e realização pessoal. Os jovens concordam que quando se tem um objetivo, havendo dedicação e força de vontade, todos os obstáculos podem ser vencidos. Este valor internalizado chega a gerar algumas contradições, pois mesmo afirmando não ser possível cursar uma universidade devido à necessidade de trabalhar e à desvantagem no preparo para o vestibular, declarase que "tudo é possível quando realmente se quer algo e se batalha" para conseguir. Fica aparente, portanto, que o autoconceito elevado destes alunos não está articulado com a realidade que percebem, a realidade de que sua escola não os está preparando para assumir os objetivos que gostariam de traçar, forçando-os a estabelecer metas que ficam aquém das suas vontades.

A responsabilidade do Ensino Médio pela preparação do aluno para a continuidade dos estudos e para a inserção no mercado de trabalho, conforme estabelece a LDB, é assim deslocada para o esforço e dedicação do próprio aluno, reproduzindo os valores da ideologia liberal. A conseqüência da reprodução destas idéias é a falta de consciência do lugar que se é levado a ocupar na sociedade e, conseqüentemente, a falta de posicionamento perante o lugar que se pretende ocupar e a sociedade que se pretende construir.

\section{O sujeito do projeto de vida}

Dentre os alunos que pretendem fazer vestibular e apresentam melhores condições financeiras, pesa a opinião da família na decisão de suas carreiras profissionais, seja pelo incentivo para que sigam as carreiras que os pais e irmãos já seguem, ou pela indicação dos pais das profissões que eles acham mais adequadas para o perfil dos filhos. Estes jovens demonstram que a opinião dos familiares na decisão da carreira profissional é determinante quando a expectativa de ingressar no curso universitário se encontra ameaçada, de modo que o aluno elabora a possibilidade de não alcançar o que definiu como seu objetivo, colocando no lugar algo que pode alcançar mais facilmente, no caso, a carreira definida pelos pais.

Dentre os alunos de condições financeiras mais baixas, a influência dos pais é descrita como "coisa de novela", pois a impossibilidade de continuar os estudos após o ensino médio limita as oportunidades de escolha profissional, tornandose um fator de maior influência do que a opinião dos pais. Entretanto, chegam a discutir a possibilidade de seguir carreiras que gostem ou que ofereçam um bom retorno financeiro, mas concluem que na realidade a escolha da profissão acaba sendo determinada pelas oportunidades que aparecem, que com freqüência se resumem a seguir a profissão dos pais, carreiras que acreditam, são mais fáceis de se conseguir e mais seguras para se manter. 
As obrigações familiares, as dificuldades financeiras e a possibilidade de seguir carreiras mais seguras são, portanto, fatores que têm impossibilitado a definição consciente de objetivos, principalmente no que diz respeito às profissões. $\mathrm{Na}$ maioria dos casos, as capacidades, as habilidades e os desejos pessoais não são sequer considerados na escolha profissional, ficando o jovem voltado para aquilo que acha que pode alcançar ou para o que os outros acham que ele pode.

O que preocupa é que na maioria dos casos esta influência não é consciente, evidenciando que, com freqüência, esses jovens não têm se constituído como sujeitos dos seus projetos, mas, sim, se sujeitado a ocupar um espaço predeterminado, um espaço que quando não é o mais seguro e promissor, é aquele foi oferecido para ele. Além disso, o medo de não conseguir obter sucesso profissional e a falta de capacidade para se manter em uma profissão foram indicados como fatores que incentivam a seguir profissões que não sejam as desejadas pelos jovens. Assim, observa-se que além dos obstáculos impostos pela concorrência e pela falta de oportunidades, esses jovens apresentam ou a formação de um autoconceito supervalorizado que não está de acordo com a realidade em que se insere, ou a formação de um autoconceito rebaixado, que acaba por despertar a sensação de impotência e medo de assumir a responsabilidade pelos seus próprios projetos.

\section{Considerações finais}

A análise dos dados permitiu verificar que os diferentes objetivos definidos pelos alunos em seus projetos de vida estão atravessados por uma significação da sociedade que aparece sempre separada do indivíduo. Apesar de pertencerem a diferentes frações das classes populares e médias, a mesma ideologia liberal permeia o discurso destes jovens que insistem em assumir sozinhos a responsabilidade por seu sucesso e fracasso pessoal, ao mesmo tempo em que admitem ocuparem um lugar de desvantagem diante da competição do mercado de trabalho, da formação acadêmica limitada, da concorrência pelas vagas nas universidades. Esta situação se torna ainda mais preocupante quando se verifica que poucas são as condições encontradas por estes jovens para a reflexão sobre as determinações sociais, econômicas, afetivas que os levam a ocupar o lugar que ocupam na sociedade e, a partir disso, definir estratégias coletivas para ocupar o lugar que gostariam de ocupar. Assim, este jovem permanece como objeto de reprodução do modelo de sociedade atual na medida em que segue um projeto de vida estabelecido para ele, mas não por ele.

O ensino médio continua perpetuando a dualidade estrutural que colabora para a exclusão social. As escolas particulares continuam a formar a elite dirigente, que receptora da educação propedêutica, dirige-se aos cursos superiores. Enquanto isso, o aluno da escola pública continua freqüentando um ensino médio, que ainda carente de investimentos, não o prepara para a continuidade dos estudos, e pelo contrário, legitima a necessidade da educação técnica paralela capaz de inserir o aluno como força produtiva no mundo do trabalho.

Diante deste quadro, questiona-se: se o discurso liberal internalizado e o autoconceito rebaixado não dão condições para que os alunos assumam responsabilidade pelos próprios projetos, como assumirão a responsabilidade pela sociedade em que se inserem? É preciso pensar em meios para promover a discussão destes temas entre os jovens e principalmente de levantar possibilidades para que a escola pública possa assumir sua responsabilidade enquanto espaço de reflexão e formação. $O$ psicólogo, por sua vez, deve assumir a sua responsabilidade diante de tais questões, principalmente quando se propõe a trabalhar com educação, trabalho e orientação profissional.

\section{Referências}

Contini, M. L. J. (2001). O psicólogo e a promoção de saúde na educação. São Paulo: Casa do Psicólogo.

Cunha, A. (1985). Educação e desenvolvimento social no Brasil. Rio de Janeiro: Francisco Alves.

Ghiraldelli Junior, P. (2001). História da educação. São Paulo: Cortez.

Kuenzer, A. Z. (2000). Ensino médio: Construindo uma proposta para os que vivem do trabalho. São Paulo: Cortez.

Kuenzer, A. Z. (2001). Ensino médio e profissional: As políticas do estado neoliberal. São Paulo: Cortez.

Liebesny, B., \& Ozella, S. (2002). Projeto de vida na promoção saúde. In M. L. J. Contini; $\mathrm{S}$. H. 
Rey, F. G. (1995). La adecuación de la autovaloración y su significación psicológica. In Investigaciones de la personalidad em Cuba. (pp. 17-38). La Habana: Editorial de Ciências Sociales.

Vygotski, L. S. (1992). Pensamiento y palabra. In L. S. Vygotski. Obras escogidas II. (pp. 287-348). Madrid: Visor Distribuiciones.

Recebido em: 05/09/2006

Received in: 09/05/2006

Aprovado em: 29/09/2006

Approved in: 09/29/2006 